\title{
Relationship of thumb prints and lip prints among Nigerians
}

\author{
${ }^{1}$ L. H. Adamu, ${ }^{* 1}$ M. G. Taura, ${ }^{2}$ W.O. Hamman, ${ }^{3}$ S. A. Ojo, ${ }^{2}$ A. U. Dahiru, ${ }^{2}$ \\ A. A Sadeeq, ${ }^{4}$ K. B. Umar, \\ ${ }^{1}$ Department of Anatomy, Faculty of Medicine, Bayero Univeristy, Kano, P M B 3011, Kano Nigeria \\ ${ }^{2}$ Department of Human Anatomy, Faculty of Medicine, Ahmadu Bello Univeristy, Zaria P M B 1045, Samaru \\ Zaria, Kaduna State, Nigeria \\ ${ }^{3}$ Department of Veterinary Anatomy, Faculty of Veterinary Medicine, Ahmadu Bello Univeristy, P M B 1045, \\ Samaru Zaria, Kaduna State, Nigeria \\ ${ }^{4}$ Department of Physiotherapy School of Community Health Science, Shehu Idris College of Heath Science and \\ Technology, makarfi, Kaduna State, Nigeria
}

\begin{abstract}
Establishment of association between two variables in the forensic science is of paramount importance. The study was aimed to determine association of lip prints types and left thumb prints among Nigerians. A total of 820 subjects (414 male and 406 female) participated in the study. The lip prints were obtained on microscopic glass slide and developed using carbon black powder. For finger prints normal conventional method of using ink pad was employed. The data were analyzed using chi square test and $P<0.05$ was considered as level of significance. The result shows the percentage distribution of lip prints as Type $V$ (31.39\%) as the predominant and the least was Type I' (0.57\%). For thumbprints in both sexes loop exhibit high percentages and arches the least. The association between lip prints and left thumb print shows statistically significant correlation in Lower Right Medial (LRM) $\left(\chi^{2}=7.95, P=0.0002\right)$ and Lower Left Lateral (LLL) $\left(\chi^{2}\right.$ $=5.42, P=0.02)$ compartments only. In conclusion, the lip print was found to be statistically associated with left thumb prints. Hence, relationship of finger prints and lip prints can hold potential promise as supplementary tool in personal authentication.
\end{abstract}

Key words: Finger print Lip prints, Nigeria, Personal authentication

\section{Introduction}

The use of conventional methods such as use of fingerprints and lip prints are of paramount importance, since personal identification by other means such as DNA analysis is sophisticated and not available in rural and developing countries. Fingerprint in its narrow sense is an impression left by the friction ridges of human fingers. The science of fingerprints had acclaimed and reputed as panacea for individualization particularly in forensic investigations [1].

The three basic patterns of fingerprint ridges are arch (plain and tented), loop (radial and ulna), and whorl (plain and others). An arch is a pattern where the ridges enter form one side of the finger, rise in the centre forming an arc, and then exit the side of the finger and the loop is a pattern where the ridge enters from one side of a finger, form a curve and tend to exit from the same side they enter. Whereas, in the whorl pattern ridges form circularly around a central point on the finger $[2,3]$

The crucial events for the establishment of the epidermal ridge pattern take place from the $10^{\text {th }}$ to $16^{\text {th }}$ weeks of development $[4,5,6,7,8,9,10,11]$. The $11^{\text {th }}$ week marked the period of formation of primary ridges. These established the future surface patterns which become well pronounced at the $16^{\text {th }}$ week. Because fingerprints patterns are encoded at the interface between dermis, the pattern cannot be destroyed by superficial skin injuries $[12,4,9]$. Various factors were suggested by numerous scientists to be the major driving forces in the pattern and formation of fingerprints, such factors include; Volar pad [13], Genetic factor, SMARCADIgene, [14], Boundary effects, Markel cells [15]. Several studies show little variation in the distribution of pattern of fingerprints across the continent and about $25-35 \%$ of the finger print is whorls, $60-65 \%$ is loops and arches is $5 \%$. The suggested value for Negroid population was $7 \%$ arches, $28.35 \%$ whorls and $64.55 \%$ loops $[16,3]$

The second prints of interest is lip prints, which are normal lines and fissures in the form of wrinkles and grooves present in the zone of transition of human lip between the inner labial mucosa and outer skin. The appearance of lip prints, like fingerprints vary from persons to persons [17]. The biological phenomenon of systems of furrows on the red part of human lips was first noted by anthropologists; R. Fischer who was the first to describe it in 1902 [18]. Use of lip prints in personal identification and criminalization was first recommended in France by Edmond Locard [19]. The most commonly used classification scheme of lip-prints invented by Suzuki and Tsuchihashi [20] in 1970 are: Type I; a clear-cut groove vertically across the lips, type I!; a partial-length groove of type I, type II; a branched groove, type III; an intersected groove type IV; a reticular pattern and finally type $\mathrm{V}$; other types. 
Cottone and Standish [21], reported in their book outline of forensic dentistry, that cheiloscopy (study of lip prints) is one of its special techniques used for personal identification, and Ball [22] has also reported the history of lip prints and importance of its evidence in the courts as well as its status as a source of forensic evidence. Hence, it was proved beyond doubt that lip prints are as good as fingerprints in criminal identification and can be definitely be used when no other means of traditional method of identification are available [23]. The various processes from which the face (including lips) develops can be identified at the end of $4^{\text {th }}$ week and the overlying skin of the lip is derived from the ectoderm and musculature is derived from mesoderm of the second pharangeal arch [24]. The lip prints develop in the same weeks of embryological life as the lip [25].

Studies of association between finger print and lip prints are scanty in the literature. Reference data on various forms of personal identification such as fingerprints, lip prints etc are of paramount importance in solving security findings. The present study aims to determine the percentage distribution of lip print and left thumb prints as well as the association between lip print and left thumb prints among Nigerian population

\subsection{Subject and study location}

\section{Materials and Methods}

The data was collected from 820 subjects (414 males and 406 females) aged 12-20 years from Demonstration secondary school Ahmadu Bello University, Zaria-Nigeria, After Informed consent was sought from the students whose age was 18 years and above, and from class teachers for the students whose age fell below 18 years. All the participants were apparently healthy with absence of external congenital malformations, physical deformities or inflammation.

\subsection{Finger prints collection}

After the left thumb was cleaned with tissue paper, the subjects were made to roll the tip of their left thumb across the surface of an already made ink-stained pad, ensuring that the ink covered the entire pattern area. The finger was then transferred to a white paper to obtain the print and analyzed using magnified hand lens [26].

\subsection{Lip prints collection}

The subjects were made to stand in a relax position and the lips were cleaned with the tissue paper. Care was taken to ensure that no traces of the tissue paper were left on the lips. A clear new microscopic glass slide was placed on the relaxed lips of the subject in a single motion. The glass slide was then removed from the surface of the lip and carbon black powder was poured on the surface of the slid that is in contact with the lips, then the excess powder was dusted by mouth blow, this led to the production of well developed lip prints on the slide ready for preservation and analyses. The glass slide was then placed on an area provided on the questionnaire (with left and right, superior and inferior sides in consideration). Finally, a transparent cello tape was used to cover the print as well as attaching the slide to the questionnaire. Care was taken to avoid formation of bubbles and wrinkles on the glass slide [27]. The lip print was then divided into five quadrants for both lower and upper lip for an accurate estimation of the lip prints patterns (Fig. 1). Using modified Hassan and Fahamy [28] method

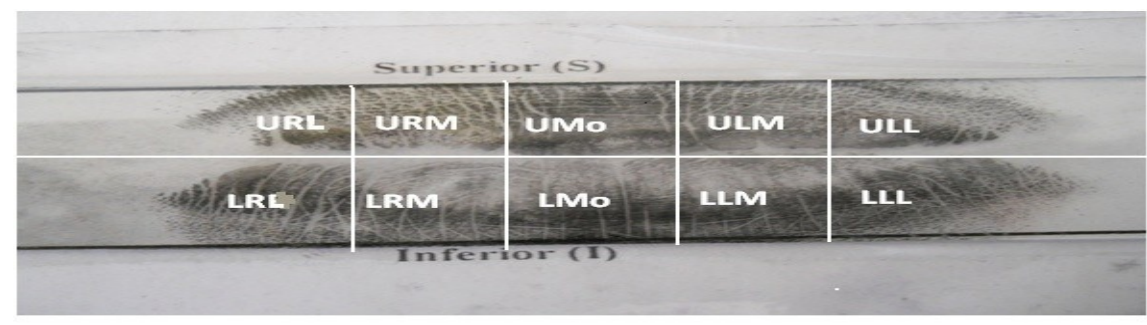

Figure 1: A well developed lip prints of a participant divided into ten quadrants ready for analysis

Key; $\mathrm{ULL}=$ Upper left lateral, $\mathrm{LLL}=$ Lower left lateral, ULM $=$ Upper left medial, $\mathrm{LLM}=$ Lower left middle, $\mathrm{UM}_{\mathrm{o}}=$ Upper median, $\mathrm{LM}_{\mathrm{o}}=$ Lower median, upper, $\mathrm{URM}=$ Upper right medial, $\mathrm{LRM}=$ Lower right middle, $\mathrm{URL}=$ Upper right lateral and $\mathrm{LRL}=$ Lower right lateral compartments 


\subsection{Statistical analysis}

The data was presented in form of chart using simple percentage and Chi-square test was used to test for association between the variables. Level of significance was considered at $\mathrm{p}<0.05$. Analyse it statistical software for Microsoft excel, version 2.26, 2012 was used for the analysis

\section{Result}

Fig. 2 shows percentage distribution of the pattern of left thumb prints according to sexes. In males the most common fingerprints pattern were loops (54.8\%), followed by whorls $(39.9 \%)$ and arches (5.3\%). Similar pattern was seen in females as loops (52\%), Whorls (39.4\%) and Arches (8.6\%). In both sexes loops exhibit high percentages and arches least.

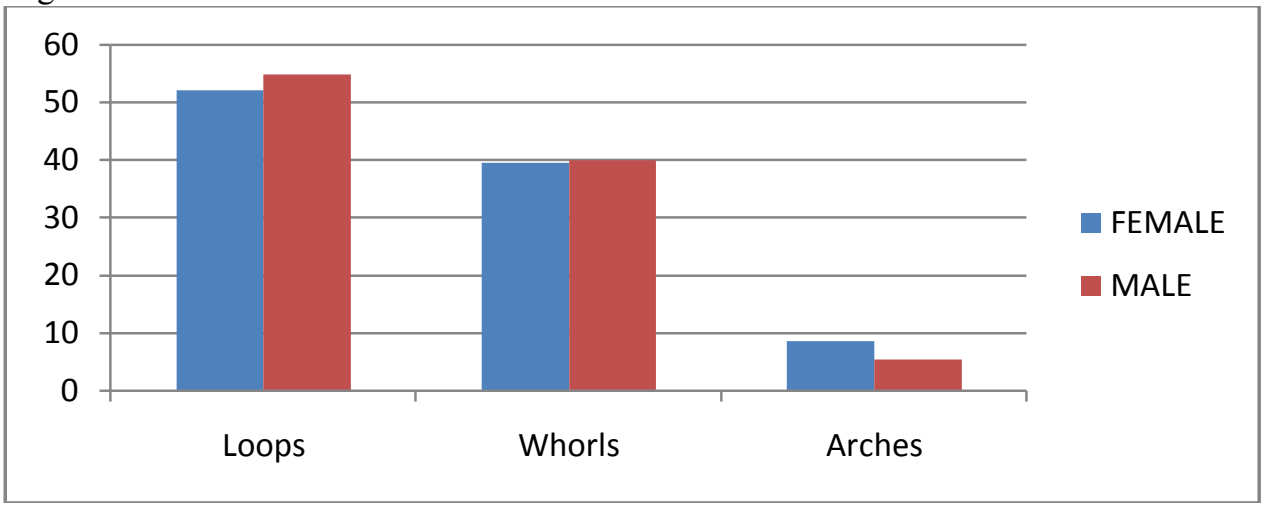

Figure 2: Percentage distribution of the pattern of left thumbprints according to sex

In Fig. 3 the percentage distribution of lip print shows that the most frequent lip pattern in the male is Type V (31.48\%), followed by type III (26.60\%), type I (15.99\%), type IV (14.45\%),type II (11.09\%) and the least was type I' $(0.55 \%)$. In female the type V (31.53\%) was predominant, followed by type IV (22.91\%), type III (21.69\%), type I (13.70\%), type II (9.52\%) and the least was type I' $(0.57 \%)$.

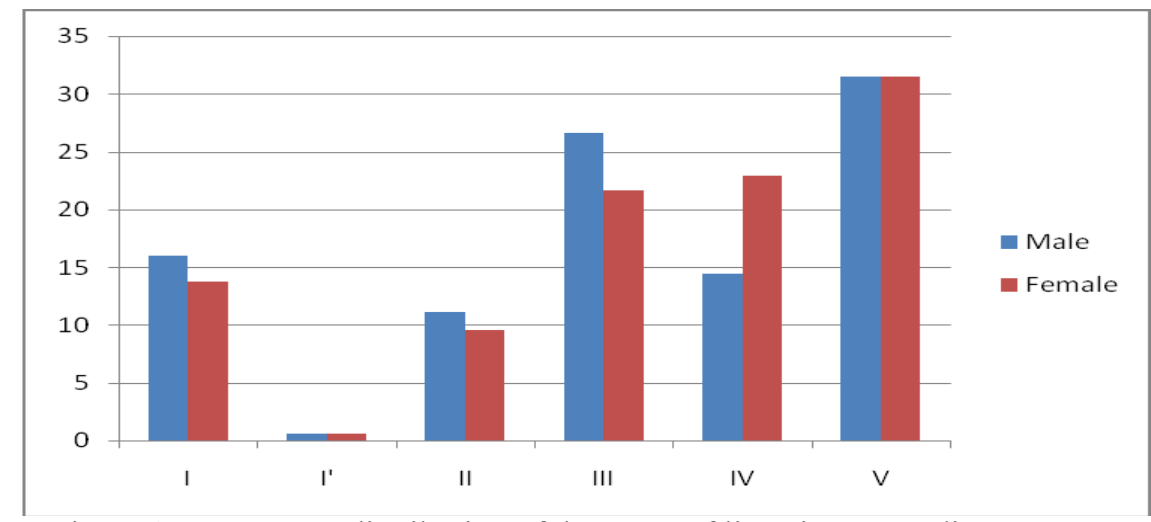

Figure 3: Percentage distribution of the types of lip prints according to sexes

The association between lip prints and finger print was shown in Table 1 to 5 , the result shows that left thumb shows statistically significant association with $\operatorname{LRM}\left(\chi^{2}=7.95, \mathrm{P}=0.0002\right)$ and $\operatorname{LLL}\left(\chi^{2}=5.42, \mathrm{P}=0.02\right)$ in Tables 1 and 4 respectively and there was no statistically significant association with the rest of the compartments

Table 1: Association between left thumb prints with upper and lower left lateral (ULL and LLL) compartments

\begin{tabular}{|c|c|c|c|c|c|c|c|c|c|}
\hline Left Thumb & Compartment & I & $\mathrm{I}^{\prime}$ & II & III & IV & V & $\mathrm{X}^{2}$ & $\mathrm{P}$ \\
\hline Arches & & 5 & 0 & 4 & 24 & 7 & 17 & & \\
\hline Loops & ULL & 42 & 0 & 42 & 160 & 36 & 158 & 11.49 & 0.3207 \\
\hline Whorls & & 39 & 1 & 30 & 142 & 21 & 92 & & \\
\hline Arches & & 5 & 2 & 11 & 17 & 4 & 18 & & \\
\hline Loops & LLL & 39 & 0 & 78 & 121 & 35 & 165 & 20.91 & 0.0217 \\
\hline Whorls & & 45 & 3 & 68 & 90 & 25 & 94 & & \\
\hline
\end{tabular}


Table 2: Association between left thumb prints with upper and lower left medial (ULM and LLM) compartments

\begin{tabular}{ccrrrrrrrr}
\hline Left Thumb & Compartment & I & I' & II & III & IV & V & $X^{2}$ & P \\
\hline Arches & & 6 & 0 & 4 & 15 & 11 & 21 & & \\
Loops & ULM & 50 & 3 & 44 & 133 & 96 & 112 & 10.23 & 0.4208 \\
Whorls & & 41 & 4 & 32 & 116 & 64 & 68 & & \\
\hline Arches & & 7 & 1 & 8 & 11 & 13 & 17 & & 0.8759 \\
Loops & LLM & 72 & 2 & 54 & 73 & 107 & 130 & 5.22 & \\
Whorls & & 61 & 1 & 43 & 56 & 81 & 83 & & \\
\hline
\end{tabular}

Table 3: Association between left thumb prints with upper and lower median (UM and LM) compartments

\begin{tabular}{|c|c|c|c|c|c|c|c|c|c|}
\hline Left Thumb & Compartment & I & $I^{\prime}$ & II & III & IV & $\mathrm{V}$ & $X^{2}$ & $\mathrm{P}$ \\
\hline Arches & \multirow{2}{*}{ UM } & 14 & 0 & 0 & 8 & 22 & 13 & & \multirow{2}{*}{0.3021} \\
\hline Whorls & & 67 & 5 & 13 & 22 & 126 & 92 & & \\
\hline Whorls & LM & 104 & 0 & 18 & 12 & 111 & 80 & & 0.3335 \\
\hline
\end{tabular}

Table 4: Association between left thumb prints with upper and lower right medial (URM and LRM) compartments

\begin{tabular}{|c|c|c|c|c|c|c|c|c|c|}
\hline Left Thumb & Compartment & I & $I^{\prime}$ & II & III & IV & V & $X^{2}$ & $\mathrm{P}$ \\
\hline Arches & \multirow{3}{*}{ URM } & 6 & 0 & 5 & 19 & 13 & 14 & & \multirow{3}{*}{0.6136} \\
\hline Loops & & 54 & 4 & 33 & 129 & 89 & 129 & 8.16 & \\
\hline Whorls & & 52 & 2 & 23 & 112 & 52 & 84 & & \\
\hline Arches & \multirow{3}{*}{ LRM } & 2 & 2 & 11 & 7 & 16 & 19 & & \multirow{3}{*}{0.0002} \\
\hline Loops & & 78 & 0 & 43 & 78 & 92 & 147 & 33.41 & \\
\hline Whorls & & 57 & 1 & 40 & 66 & 73 & 88 & & \\
\hline
\end{tabular}

Table 5: Association between left thumb prints with upper and lower right lateral (URL and LRL) compartments

\begin{tabular}{|c|c|c|c|c|c|c|c|c|c|}
\hline Left Thumb & Compartment & $\mathrm{I}$ & $\mathrm{I}^{\prime}$ & II & III & IV & $\mathrm{V}$ & $X^{2}$ & $\mathrm{P}$ \\
\hline Arches & \multirow{3}{*}{ URL } & 7 & 0 & 6 & 22 & 3 & 19 & & \multirow{3}{*}{0.8620} \\
\hline Loops & & 33 & 1 & 32 & 152 & 39 & 181 & 5.41 & \\
\hline Whorls & & 28 & 1 & 25 & 125 & 25 & 121 & & \\
\hline Arches & \multirow{3}{*}{ LRL } & 6 & 1 & 14 & 11 & 6 & 19 & & \multirow{3}{*}{0.3606} \\
\hline Loops & & 45 & 1 & 70 & 101 & 33 & 188 & 10.96 & \\
\hline Whorls & & 37 & 1 & 60 & 86 & 20 & 121 & & \\
\hline
\end{tabular}

\section{Discussion}

In forensic sciences dermatoglaphic has traditionally been used to differentiate between populations, due to their unchanging genetic base and differences between populations [29, 30, 31]. However, establishment of association between two dermatoglaphic variables in forensic sciences is scanty in the literature. The result of the present study shows that the percentage distribution of left thumbprints patterns falls close to the expectation of $25-35 \%$ of the finger prints as whorls, $60-65 \%$ as loops and arches as 5\% and also not far from suggested value for Negroid population which shows the percentage as $7 \%$ arches, $28.35 \%$ whorls and $64.55 \%$ loops $[3$, 16]. The finding is also similar to the finding of Danborno and Idris [32] in Hausa ethnic group with the result showing that Hausa males had $30.15 \%$ as whorls, $65.91 \%$ as loops and $3.95 \%$ arches. In females $29.33 \%$ had whorls, $61.27 \%$ had loops and 9.29\% were having arches. Osunwoke et al.[33] on Okrika and Ikwerre ethnic 
groups of Nigeria also showed that the ulnar loops for Okrika population were $46.42 \%$, whorls $37.77 \%$, arches $14.12 \%$ and radial loops $1.71 \%$. The Ikwerre population had the ulnar loops of $56.46 \%$ which was higher than that of the Okrika population, whorl $24.42 \%$, arches $15.89 \%$ and radial loops $3.23 \%$

In the percentage distribution of the lip prints little variation was noticed with respect to previous studies. Hassan and Fahmy [28] in their studies of the pattern of lip print in upper Egyptians found that type IIa was the most frequent one in the upper lip in males with a percentage of 39\%. Type IV was the most frequent type in the upper lip in females with a percentage of $44.4 \%$. Type Ia and IIc were of a higher percentage $(32.2 \%)$ in the lower lip in males. Type Ia was the most frequent one in the female lower lip. In lower Egyptians it was reported that inheritance of lip prints in cleft lip and plate in children shows the following pattern among the parents. In fathers: type IIa is significantly higher in the upper lip. In mothers: type IIa was significantly higher in both the upper and lower lips. Type $\mathrm{O}$ (a new type) which is under type $\mathrm{V}$ was significantly higher in mothers than the fathers [34]

It was also reported that type I was dominant in females in the lower lips and that males tend to have different patterns in all compartments and the female tend to have the same patterns in all compartments [35]. According to Mahaswari [36] males recorded that the maximum number of individuals has Type II lip prints (31.61\%) and the minimum number of individuals had type IV lip print $(0.57 \%)$. It is recorded that among females maximum numbers of individuals have type II lip prints (43.79\%) and minimum of individuals had type IV $(0.99 \%)$. Saraswathi et al. [37] also noted that males and females had 39.5 and $36.5 \%$ intersecting pattern, respectively. El Dormaty et al. [38], stated that a total of $72.67 \%$ of lip prints showed the same groove pattern in the upper right and upper left areas (78.89\% of females and $64.79 \%$ of males), while $75.36 \%$ of the prints showed the same groove pattern in the lower right and lower left areas $(74.81 \%$ of females and $76.06 \%$ of males). Nine types of grooves were recorded in Saudi Arabia at Almedinah Al-monawarah province lips. Horizontal groove with other forms was the highest (68.7\% in females and $42.7 \%$ in males). It was recorded that males $25.29 \%$ had Type I, $31.61 \%$ with Type II, $14.94 \%$ with Type III, $0.57 \%$ with Type IV and $27.59 \%$ with Type V lip prints. In females $22.89 \%$ were having Type I, $43.79 \%$ with Type II, $12.94 \%$ with Type III, $0.99 \%$ with Type IV and $19.40 \%$ with Type V lip prints [39]. These variations of distribution of the lip prints and finger prints may be linked to the genetic influences which vary with respect to different races.

Several studies established association of lip prints and sex [40, 41, 42], the present study further analyzed the association of left thumb prints and lip prints. The result have shown statistically significant association between left thumb prints and lip prints in LLL and LRM compartment, the main importance of this association is that the thumb prints is related to the lip print types and both the two prints have relationship of been controlled by genetic factors. This study is in agreement with the study of Nagasupriya et al., carried out on Indian population [43] despite the different methods employed in the analysis of the lip prints. Lip prints, as one of the dermatoglyphics like fingerprint, have also been used as genetic makers in many congenital and clinical disorders [44].

\section{Conclusion}

The percentage distribution of the prints gives an idea about different pattern of the predominance of the lip prints across the globes. Despite the use of different methodology in thumbprint and lip prints collection, the left thumb print was found to be statistically associated with some compartment of the lips. Hence, relationship of finger prints and lip prints can hold potential promise as supplementary tool in personal identification as well as genetic makers in many congenital and clinical disorders

\section{Acknowledgement}

We thank all those who volunteered to participate in this research.

\section{References}

[1] S.S. Adebisi, Recent Challenges and Advancement: A literary review, The Internet Journal of Biological Anthropology, 2(2), 2009, DOI: $10.5580 / 18 f 3$. ISSN: 1939-4594

[2] G. Langenberg, Are one's fingerprints similar to those of his parents in any discernable way? Scientific American, 2005, http://www.scientific american.com

[3] E.R. Henry, Classification and uses of fingerprints London. George Rutledge and Sons, Limited, 1900, 54

[4] W. Babler, Embryogenic development of epidermal ridges and their configurations. In: C. Plato, R. Garruto, and Schaumann, B. (Eds). Dermatoglyphics: Science in Transition, Wily-Liss, Inc. 1991

[5] K. Bonnevie, Die crsten entwick lungstadien der papillarmuster der menschlichen fingerballen. Nyt. Mag. Naturvidensicaaberne, $65,1927,19-56$.

[6] E.J. Gould, A topographic study of the differentiation of the dermatoglyphic in the human embryo. PhD Dessertation, Tulane University, 1948

[7] A. Hale, Morphogenesis of volar skin in the human foetus, American Journal of Anatomy, 91, 1951, $147-180$.

[8] W. Hirsch, Morphological evidence concerning the problem of skin ridge formation. Journal of Mental Deficiency Research, 17, $1973,58-72$.

[9] M. Okajima, Development of dermal ridges in the fetus. Journal of medical Genetic, 12, 1975, $234-250$.

[10] L. Penrose, P. O'Hara, The development of epidermal ridge. Journal of Medical Genetic, 10, 1973, $201-208$. 
[11] J. Schaeuble, Die Entstenhung der palmaren Triradien. Z. Morphologische des Anthropologie, 31, 1932, 403-438.

[12] M. Kucken, A.C. and Newell, A model of fingerprints formation. European Physics Latter, 68(1), 2004, 141-146.

[13] K. Bonnevie, Was lehrt die embryologie der papillar muster uber ihre bedeutung als rassen-und familiencharakter. Part I and II. Z Inducts. Abstammver, 50, 1929, 219-274.

[14] C.N. Adra, J. L. Donato, R. Badovinac, F. Syed, R. Kheraj, H. Cai, C. Moran, M. T. Kolker, H. Turner, Weremowicz, S. T. Shirakawa, C.C. Morton, L.E. Schnipper, and R. Drews, SMARCAD1, a novel human Helicase family-defining member associated with genetic instability: cloning, expression, and mapping to 4q22-q23, a band rich in breakpoints and deletion mutants involved in several human diseases. Genomics, 69 (2), 2001, 162-73.

[15] M. Kucken, and A.C. Newell, Fingerprints formation, Journal of Theoretical Biology, 235, 2005, 71-83.

[16] H. Cummins, and C. Midlo, Fingerprints, Palms and Soles. Research Publishing Company, Inc. 46, 1976

[17] I.M. Caldas, T. Magalhaes, and A. Afanso, Establishing identity using cheiloscopy and palatoscopy. Forensic science international, 165(1), 2007, 1-9.

[18] J. Kasprazak, Possibilities of chieloscopy. Forensic Science International, 46, 1990, 145-151.

[19] C.J. Thomas, and C.W. van-Wyk, The palatal rugae in identification. Journal of Forensic Odontostomatology, 6 (1) $1988,21-25$.

[20] K. Suzuku, and Y. Tsuchihashi, A new attempt of personal idenfication by means of lip print. Journal of India Dental Association, (42 (1), 1970, 8-9.

[21] J.A. Cottene, and S.M. Standish, Text book of outline of forensic dentistry. Special Tech., (Cheiloscopy), 1981,135

[22] J. Ball, The current status of lip prints and their use for identification. Journal of Forensic Odontostomatology, 20 (2), $2002,43-46$.

[23] A. Aggrawal, The importance of lip prints (Forensic files), (2004) http://lifeloom.com//II2Aggrawal.htm. Retrieved on February, 2010

[24] I. Singh, Text book of human embryology. Jaypee Brothers, (2005), Pp. 231-236

[25] Y. Tsuchihashi, Studies on Personal Identification by means of lip prints. Forensic Science international, 3, 1974, 233-284

[26] G.S. Oladipo, and B.E. Akanigha, Dermatoglyphic patterns in androgenetic alopecia in a south eastern Nigerian population. Journal of Experimental and Clinical Anatomy, (2), 2005, 44-47.

[27] P. Shilpa, P. Ish, S.A. Madhu R. Gayathri, and G.V. Sowmya, A study of lip prints in relation to gender, family and blood group. International journal of Oral and Maxillofacial pathology, 1(1), 2010, 4-7

[28] F.Z. Hassan and S. M. Fahmy, The pattern of lip prints in upper Egyptians. Assiut Medical Journal, 1 (4), 1977, 477-486

[29] D. Loesch, Minutiae and clinical genetics, Journal of Mental Deficiency and Research, 17, 1973, 97-105.

[30] Loesch, D. Quantitative Dermatoglyphics: Classification, Genetics and Pathology, Oxford University Press, Oxford, 1983.

[31] J. Dankmeijer, J. M. Waltman, and A. G. DeWilde, Biological foundations for forensic identifications based on fingerprints, Acta Morphol. Neerlando Scandinavia 18, 1980, 67-83

[32] B. Danborno, and G. Idris, Digital dermatoglypics of Hausas Ethenic Group of Nigeria. Journal of Experimental and Clinical Anatomy, 6(2), 2007, 36-40

[33] E.A. Osunwoke, K.S. Ordu, J. Hart, E. Esomonu, and F. B. Tamunokuro, A study on the dermatoglyphic patterns of Okrika and Ikwerre ethnic groups of Nigeria. Scientia Africana, 7 (2), 2008, 143-147.

[34] M. Weil, M.S. Saad, H.K, Assem, F.Z. Hassan and M. A. El-otiefy, Genetic Studies on the Inheritance of Lip Prints in-Cleft Lip and Palate. Egyptian Journal of Plastic Reconstractrive Surgery, 29 (1) 2005, 9-12, 2

[35] S.P. Vahanwahal, and D.K. Parakh, Study of lip prints as an aid to forensic methodology. Journal of Indian Dental Association, 71, 2000, 269-271.

[36] T.N.U. Maheswari, lip prints.PG dissertation, department of oral medicine and Radiology, Saveetha Dental College and hospitals, Chennai, 2005

[37] T.R. Saraswith, G. Mishra, K. Ranganathan, Study of lip prints. Journal of forensic Dental Science, 1, 2009, 28-31.www.jfds.org

[38] M.A., El-Domiaty, S.A. Al-gaidi, A.A. Eleya, M.D.E. safwit, and S.A. Galal, Morphological patterns of lip prints in Saudi Arabia at Almedinah Al-monawarah province. Forensic Science International, 200, 2010, 171-179.

[39] H. Singh, P. Chikara, and S. RituSingroha, Lip prints as evidence. Journal of Punjab Academic of Forensic Medical Toxicology, 2011, 23-25.

[40] L.H. Adamu, M.G. Taura, W.O. Hamman, S.A. Ojo A.U. Dahiru, A.A. Sadeeq, A.D. Ibrahim, Association of lip print and sex among Nigerians, Nigerian Journal of Basic and Clinical Science, 9 (2), 2013, 84 - 88 (in press)

[41] S.M. Gondivker, D.S. Inducker, and R. Bhowate, Cheiloscopy for sex determination. Journal of Forensic Dental Science.1, 2009, 56-60.

[42] S.N. Ramandeep, C.A. Preeti, and R. Kawar, Cheiloscopy as an aid to forensic methodology. Indian Journal of Comprehensive Dental Care, 1(1), 2011, 57-60

[43] A. Nagasupriya, R. Dhanapal, K. Reena, T.R. Saraswathi, and C. R. Ramachandran. Patterns: A crime solver, Journal of Forensic Dental Science, 3, 2011, 3-7

[44] T.Y. Afaf, S. Abd-Elwances, and A. El-Awdan, The inheritance of lip prints patterns. Tanta Medical Journal, 1(1), 1987, 26 